\title{
DEVELOPMENT OF HIGH PERFORMANCE DETECTOR TECHNOLOGY FOR UV AND NEAR IR APPLICATIONS
}

\author{
Ashok K. Sood ${ }^{1}$, John W. Zeller ${ }^{1}$, Parminder Ghuman', Sachidananda Babu', and Nibir K. Dhar ${ }^{3}$ \\ ${ }^{1}$ Magnolia Optical Technologies Inc., 52-B Cummings Park, Woburn, MA 01801 \\ ${ }^{2}$ NASA Earth Science Technology Office, Greenbelt, MD 20771 \\ ${ }^{3}$ U.S. Army Night Vision and Electronic Sensors Directorate, Fort Belvoir, VA 22060
}

\begin{abstract}
Sensing and imaging for ultraviolet (UV) and near infrared (NIR) bands has many applications for NASA, defense, and commercial systems. Recent work has involved developing UV avalanche photodiode (UV-APD) arrays with high gain for high resolution imaging. Various GaN/AlGaN $p-i-n$ (PIN) UV-APDs have been fabricated from epitaxial structures grown by MOCVD on GaN substrates with avalanche gains higher than $5 \times 10^{5}$, and significantly higher responsivities. Likewise, the $\mathrm{SiGe}$ material system allows the demonstration of high-performance detector array technology that covers the 0.5 to $1.7 \mu \mathrm{m}$ wavelength range for visible and NIR bands of interest. We have utilized SiGe fabrication technology to develop Ge based PIN detector devices on $300 \mathrm{~mm}$ $\mathrm{Si}$ wafers. We will discuss the theoretical and experimental results from electrical and optical characterization of the detector devices with various $n^{+}$region doping concentrations to demonstrate low dark currents below $1 \mu \mathrm{A}$ at $-1 \mathrm{~V}$ and high photocurrent. Recent results from these detector arrays for UV and NIR detection will be presented.
\end{abstract}

\section{GAN/ALGAN UV AVALANCHE PHOTODIODE DEVELOPMENT}

Detection of shorter UV wavelengths allows for increased spatial resolution, smaller pixels, and larger formats. Figure 1 shows a schematic cross-sectional view of the epitaxial layers and device structure for $\mathrm{Al}_{0.05} \mathrm{Ga}_{0.95} \mathrm{~N}$ UV-APDs [1].

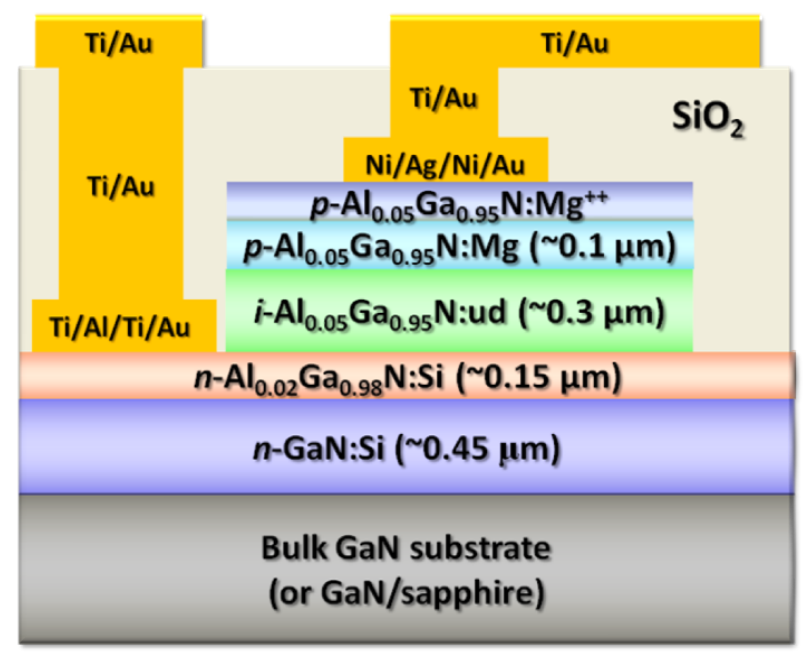

Figure 1. Device structure cross-section of GaN $p-i-n$ APD on bulk GaN substrate [1].

Figure 2 presents the current-voltage characteristics and avalanche gain for an $\mathrm{A}_{10.05} \mathrm{Ga}_{0.95} \mathrm{~N}$ UV-APD operating at $\sim 280 \mathrm{~nm}$ [2]. Under dark conditions, the device demonstrated low leakage current under $1 \mathrm{pA}$ (corresponding to dark current density of less than $10^{-7}$ $\mathrm{A} / \mathrm{cm}^{2}$ ) up to a reverse voltage of around $60 \mathrm{~V}$. We believe that low defect density native substrates and high-quality metal organic chemical vapor deposition (MOCVD) epitaxial growth technologies are the keys to the successful implementation of robust high gain, large area UV detectors. 


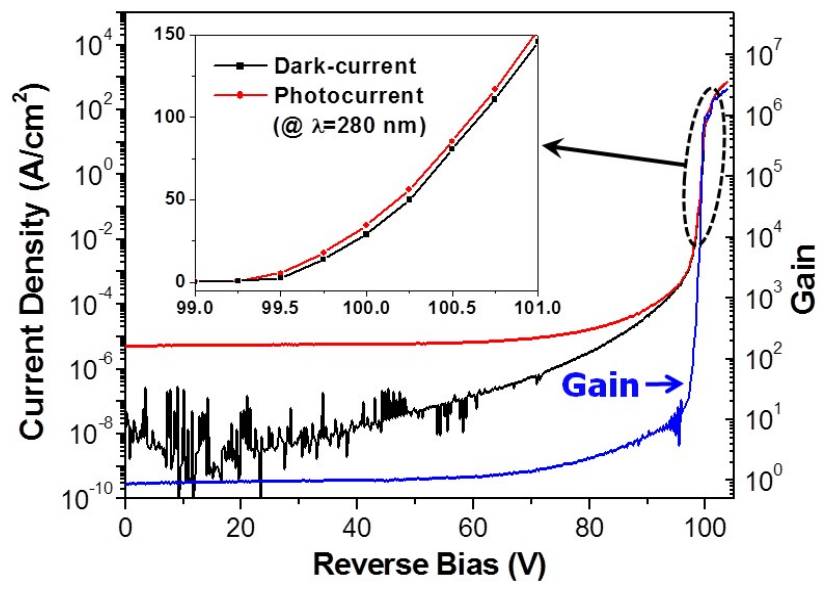

Figure 2. Current density and gain plotted vs. reverse bias for $\mathrm{Al}_{0.05} \mathrm{Ga}_{0.95} \mathrm{~N}$ UV-APD with mesa diameter of $30 \mu \mathrm{m}$ with and without UV illumination at $280 \mathrm{~nm}$. Inset shows dark current and photocurrent plotted over $99 \mathrm{~V}$ to $101 \mathrm{~V}$ reverse bias range [2].

The detection wavelength of interest in the UV band, given the utilization of YAG lasers, is $355 \mathrm{~nm}$. UV detection devices operating at this wavelength are very achievable with the $\mathrm{AlGaN}$ material system. We are currently working on optimizing the GaN/AlGaN material growth for $355 \mathrm{~nm}$ peak detector performance (Figure 3) [3].

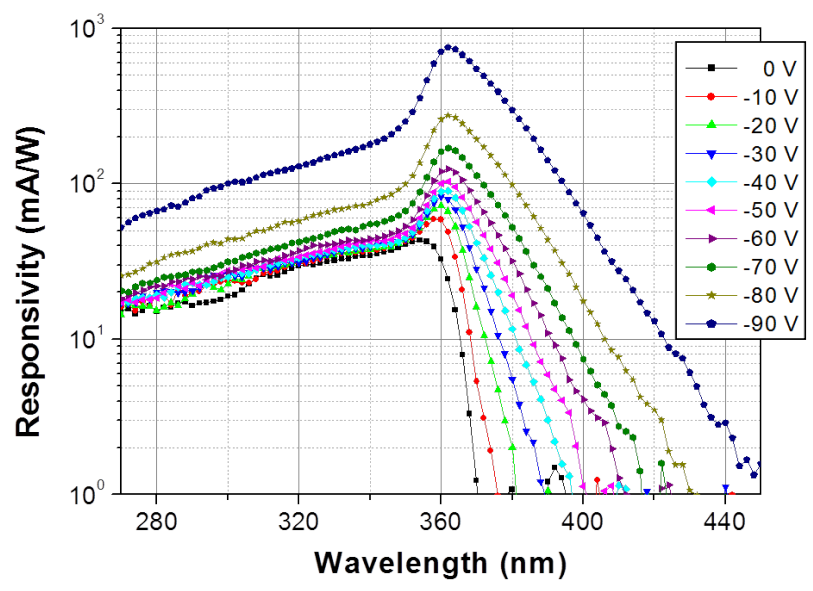

Figure 3. Reverse-biased voltage-dependent spectral response of photocurrent measured at room temperature for $70 \mu \mathrm{m}$ diameter $\mathrm{Al}_{0.05} \mathrm{Ga}_{0.95} \mathrm{~N} p-i-n$ UV-APD, showing peak responsivity at $354 \mathrm{~nm}$ under zero bias [3].

\section{SIGE VISIBLE-NIR DETECTOR ARRAY DEVELOPMENT}

SiGe offers a low-cost means for developing visible to near-infrared (vis-NIR) sensors that do not require any cooling and can operate typically from $\sim 0.4-1.6 \mu \mathrm{m}$, which range can be extended further up to $2 \mu \mathrm{m}$, e.g., with inclusion of quantum dots. The attractive features of $\mathrm{SiGe}$ based detectors and detector arrays include taking advantage of silicon-based technology that can enable very small feature sizes and compatibility with silicon CMOS readout integrated circuits (ROICs) for signal processing.
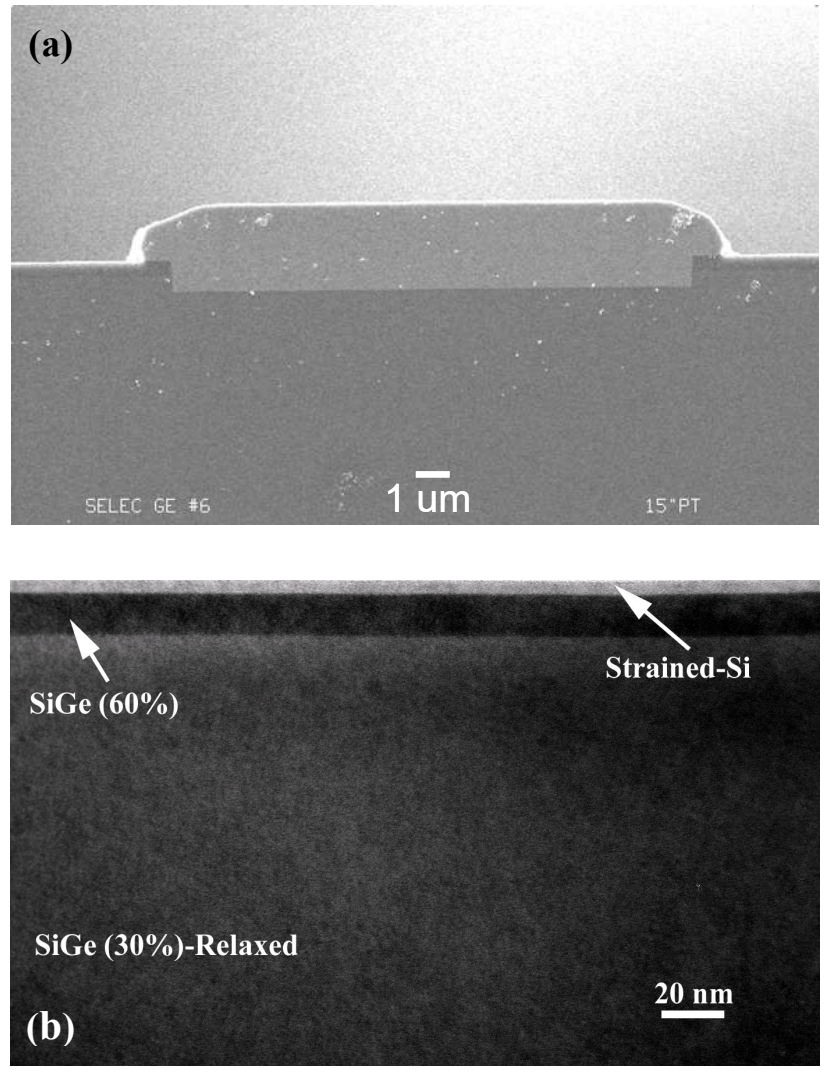

Figure 4. (a) Scanning electron microscope (SEM) cross-section micrograph of selective-epitaxial grown region of Ge-on-Si test structure (b) Transmission electron microscopy (TEM) cross-section micrograph of strained $\mathrm{Si} /$ strained $\mathrm{SiGe}(60 \% \mathrm{Ge}) /$ relaxed $\mathrm{SiGe}$ $(30 \% \mathrm{Ge})$ high-mobility heterostructure. 
SiGe epitaxial growth processes are compatible with both front- and back-end $\mathrm{Si}$ CMOS fabrication technologies. An attractive feature of CMOScompatible SiGe NIR detectors and imaging arrays is that they can be fabricated on 12-inch $(300 \mathrm{~mm}) \mathrm{Si}$ wafers, further decreasing costs and maximizing production output.

One significant advantage of this approach is that selective epitaxial growth of $\mathrm{SiGe}$ can be utilized to heterogeneously integrate $\mathrm{SiGe}$ photodiodes with CMOS circuitry, using manufacturing infrastructure that is already widely installed for production of $\mathrm{SiGe}$ layers and CMOS integrated circuits. In addition to leveraging installed infrastructure and heterogeneous integration of imaging arrays with readout electronics, our approach targeted room temperature operation. This process can also be extended to include pixel designs that stack the SiGe photodiodes on top of CMOS pixel circuitry to maximize the fill factor of the imaging array.

Compared to SiGe based metal-semiconductormetal (MSM) detector devices, SiGe detectors with PIN structures are generally stable, linear, and provide fast response times, low noise, and high responsivity. In addition, Ge/SiGe PIN photodetectors have been reported that provide relatively low dark currents ranging from low $\mu \mathrm{A}$ down to $\mathrm{nA}$ (corresponding to dark current densities typically in the $\mu \mathrm{A} / \mathrm{cm}^{2}$ to $\mathrm{mA} / \mathrm{cm}^{2}$ range). Vertical SiGe-based PIN photodetector structures grown utilizing a thin buffer layer exhibit significant built-in electric fields of several $\mathrm{kV} / \mathrm{cm}$ inside the intrinsic $\mathrm{Ge} / \mathrm{SiGe}$ layers, which results in shorter transit times and less carrier recombination at dislocations or point defects and thus higher detector collection efficiency, enabling improved device quality and smaller detector dimensions [3].

Subsequently, cross-sectional off-contact TEM and XSEM analyses of the layer structure of the SiGe devices, shown in Figure 5, show material growth with well-defined layer interfaces [4]. The cross-sectional TEM image [Figure 5(a)] and XSEM results [Figure 5 (b)] of a device with screen oxide displayed uniform compositions and relatively sharp transitions between the layers. Magnification factors associated with the TEM and XSEM images are $57 \mathrm{kX}$ and $35 \mathrm{kX}$, respectively. The thicknesses of the intrinsic Ge and oxide layers were determined from the TEM image to closely match those measured from previous XSEM image data.
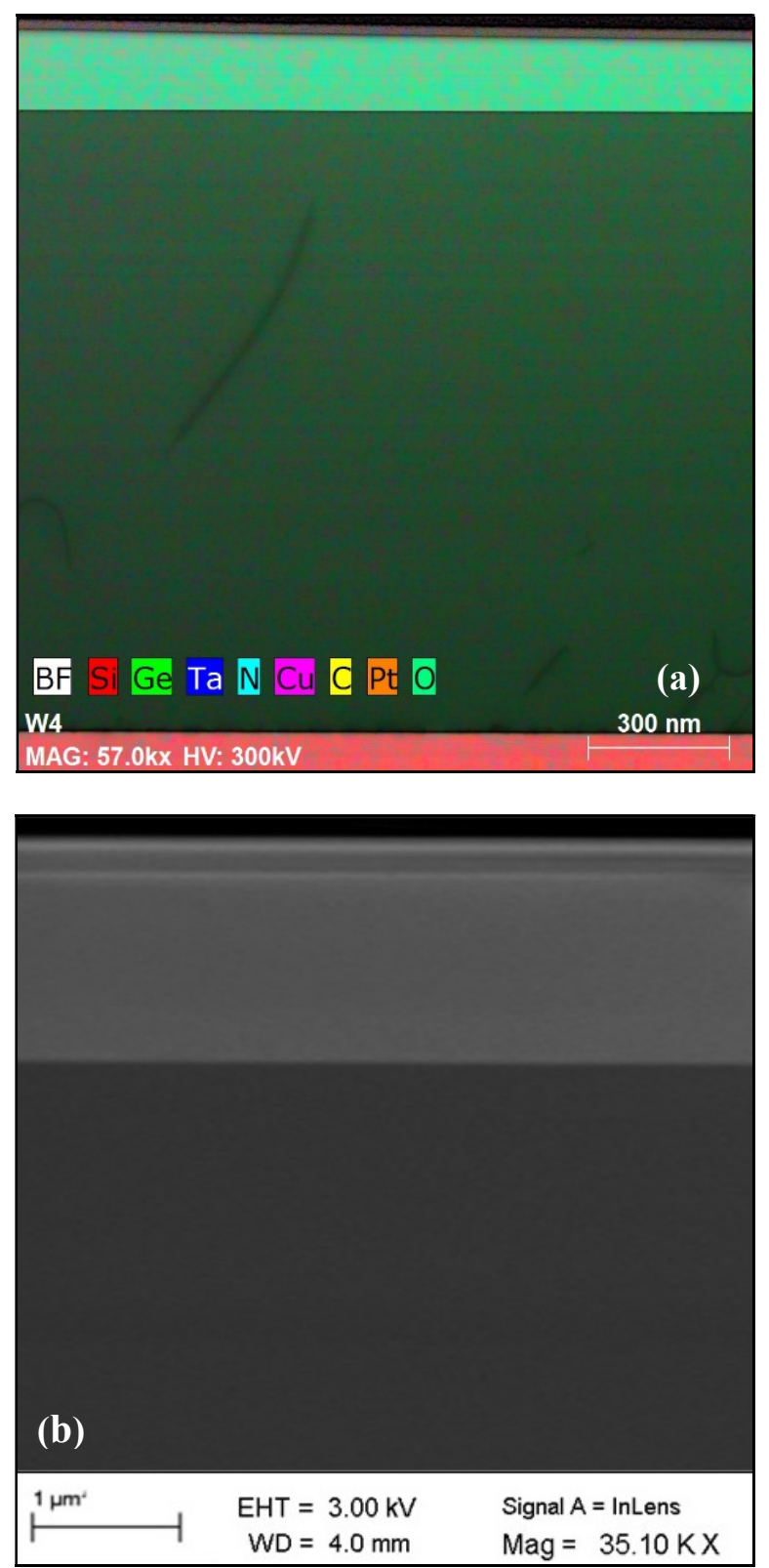

Figure 5. (a) Cross-sectional TEM image of detector device, providing material compositions (color-coded) and layer structure down to $\mathrm{Si}$ substrate. (b) Corresponding cross-sectional XSEM image with a less magnified view, i.e., showing larger area [4]. 
The I-V characterization results featured dark/leakage currents down to $100 \mathrm{nA}$ at $-1 \mathrm{~V}$, and $1 \mu \mathrm{A}$ at $-2 \mathrm{~V}$. The measured photocurrent remained relatively low, particularly above $1 \mathrm{~V}$ bias; this aspect became the primary focus for improvement in subsequent devices.
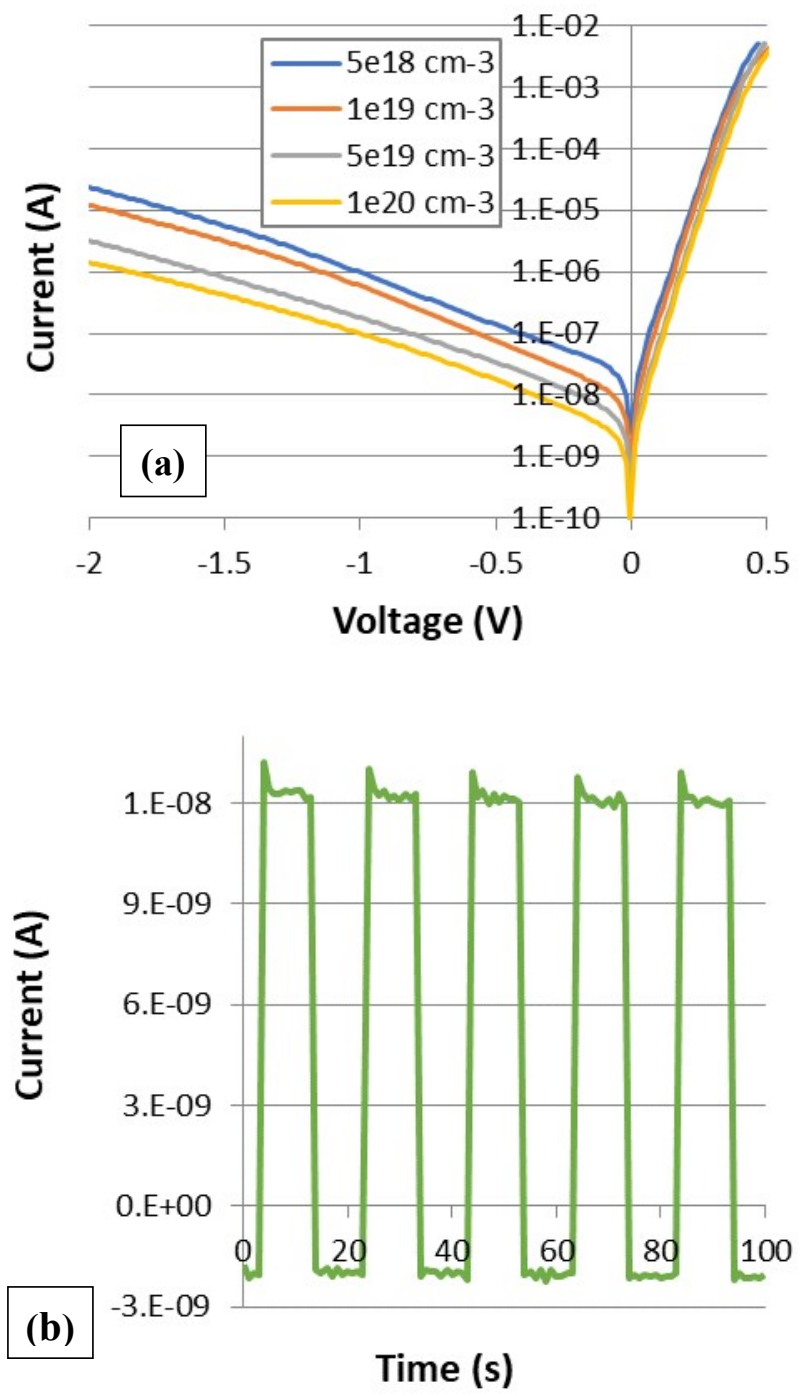

Figure 6. (a) Comparison of dark/leakage current I-V curves with various $n^{+}$region doping concentrations. (b) Time-varying photoresponse measured at $0 \mathrm{~V}$ bias.

Figure 6(a) displays the effect of doping concentration on the I-V behavior of representative devices from each quadrant. Devices corresponding to the highest doping of $10^{20} \mathrm{~cm}^{-3}$ had lowest dark currents at reverse bias. Figure 6(b) shows the associated photoresponse at zero-bias while modulating the incident NIR radiation on and off. Backside Al contacts were implemented for these devices.

\section{REFERENCES}

[1] A.K. Sood, J.W. Zeller, Y.R. Puri, R.D. Dupuis, T. Detchprohm, M.-H. Ji, S.-C. Shen, S. Babu, N.K. Dhar, and P. Wijewarnasuriya, "Development of high gain $\mathrm{GaN} / \mathrm{AlGaN}$ avalanche photodiode arrays for UV detection and imaging applications," Int. J. Engr. Res. Tech., Vol. 10, No. 2, pp. 129-150, 2017.

[2] J. Kim, M.-H. Ji, T. Detchprohm, J.-H. Ryou, R.D. Dupuis, A.K. Sood, and N.K. Dhar, " $\mathrm{Al}_{x} \mathrm{Ga}_{1-x} \mathrm{~N}$ ultraviolet avalanche photodiodes with avalanche gain greater than 105," IEEE Photon. Tech. Lett., Vol. 27, No. 6, pp. 642-645, 2015 .

[3] J. Kim, M.-H. Ji, T. Detchprohm, R.D. Dupuis, J.-H. Ryou, A.K. Sood, N.K. Dhar, and J. Lewis, "Comparison of AlGaN p-i-n ultraviolet avalanche photodiodes grown on free-standing GaN and sapphire substrates," Appl. Phys. Expr., Vol. 8, No. 12, p. 122202, 2015.

[4] A.K. Sood, J.W. Zeller, Y.R. Puri, C. Rouse, P. Haldar, H. Efstathiadis, N.K. Dhar, and P.S. Wijewarnasuriya, "SiGe focal plane array detector technology for nearinfrared imaging," Int. J. Engr. Res. Tech., Vol. 10, No. 1, pp. 81-103, 2017. 